\title{
Proposta de intervenção com adolescentes em conflito com a lei: um estudo de caso
}

\author{
Ricardo da Costa Padovani \\ Lúcia Cavalcanti de Albuquerque Williams \\ Universidade Federal de São Carlos
}

\begin{abstract}
RESUMO
Adolescentes em conflito com a lei sempre fizeram presença na sociedade. O objetivo do presente estudo consistiu em descrever uma intervenção com adolescentes em conflito com a lei utilizando estratégias de resolução de problemas. Os quatros participantes estavam em regime de internação provisória em uma instituição vinculada à Vara da Infância de uma cidade do interior de São Paulo. Instrumentos utilizados: Entrevista Individual, Escala de Transtorno de Raiva (ADS-VII), Escala de Depressão, Escala de Auto-estima, Questionário de Avaliação do Atendimento, auto-relato dos participantes e monitoramento das infrações. O programa de intervenção consistiu de 10 sessões individuais, sendo três sessões na fase de pré-teste e sete sessões na fase de intervenção. As entrevistas forneceram dados ricos sobre os perfis dos participantes, como: baixa escolaridade, histórico de violência e múltiplas infrações. Durante o estudo foi observada a diminuição dos escores de raiva em dois participantes, a auto-estima manteve-se alta e todos apresentaram uma diminuição no escore de depressão. O follow-up foi realizado apenas com dois participantes.
\end{abstract}

Palavras-chave: adolescente infrator; intervenção psicológica; resolução de problemas.

\begin{abstract}
Intervention project with young offenders: a case study

Young offenders have always marked their presence in society. The goal of the present study was to describe an intervention program with young offenders based in problem-solving strategies. The four male participants were taking part of a temporary detention program in a center for young offenders into a city of São Paulo State. Instruments used: Individual Interview, The Anger Disorder Scale (ADS-VII), Beck Depression Inventory, Self-esteem Scale, Satisfaction with Treatment Questionnaire, participants self-reports and monitoring of offenses. The intervention program consisted of 10 individual sessions, three pre-testing and seven during the intervention phase. The interviews provided enriching data about the participants' profile including: low-educational status, a history of family violence and multiple offenses. Results indicated that two participants decreased their anger scores after the intervention; high levels of self-esteem were maintained and all four participants decreased their depression levels. Follow-up data was obtained from two participants only.
\end{abstract}

Keywords: young offenders; psychological intervention; problem-solving.

Adolescentes em conflito com a lei sempre fizeram presença na sociedade. Convém lembrar que o menor envolvido em atos infracionais é um fenômeno universal.

A literatura tem mostrado que há uma convergência na descrição das características de tais jovens em diferentes culturas. Dentre as principais estão: violação persistente de normas e regras sociais, uso precoce de tabaco, bebidas alcoólicas e drogas, histórico de comportamento anti-social, envolvimento em brigas, humor depressivo, reincidência de atos infracionais, envolvimento com pares desviantes e evasão escolar (Huizinga, Loeber, Thornberry \& Cothern, 2000; Kauffman, 2001; Meichenbaum, 2001; Patterson, Reid \& Dishion, 1992; Reid \& Eddy, 2002).
Em relação aos fatores de risco para a conduta infracional pode-se destacar: histórico de violência intrafamiliar, viver em uma comunidade violenta, influência de pares, distanciamento de pessoas que não se comportam criminalmente, alta tolerância a infrações, exposição a situações de risco, disciplina e monitoramento inconsistentes dos pais e existência de condições socioeconômicas desfavorecidas (Gomide, 2003; Kauffman, 2001; Patterson \& cols. 1992; Reid \& Eddy; 2002).

Feldman (1979) destaca que a manutenção da transgressão pode ser explicada pelos efeitos reforçadores gerados pelas práticas anti-sociais (controle do grupo, ganho de status) e também pela remota possibilidade de serem surpreendidos. 
Estudos destacam que o trabalho com estratégias de resolução de problemas e com relações sociais contingentes (Gomide, 1990; Kaplan, Sadock \& Grebb, 1997) pode constituir uma estratégia metodológica eficaz no estudo com adolescentes que exibem comportamentos inadequados socialmente.

A estratégia de resolução de problemas pode ser definida (D'Zurilla \& Goldfried, 1971) como um processo cognitivo-comportamental no qual o participante aprende a ter disponível uma variedade de respostas alternativas potencialmente efetivas, aumentando a probabilidade de selecionar a resposta mais adequada. Essa estratégia permite que o indivíduo adquira habilidades para levantar informações relevantes e avaliar as consequiências envolvidas em cada ação.

Apesar da urgência em se propor soluções de intervenção para essa população, infelizmente, o que se verifica na literatura brasileira é um número reduzido de programas voltados para o seu atendimento (Carvalho, 2003; Gomide, 1990). Portanto, o desenvolvimento de novos programas de intervenção que venham contribuir nesse campo de pesquisa é de fundamental importância.

O objetivo da presente estudo consistiu em descrever uma intervenção com adolescentes em conflito com a lei utilizando estratégias de resolução de problema.

\section{MÉTODO}

\section{Participantes}

Quatro adolescentes infratores do sexo masculino, sendo três com 16 anos e um com 17 anos participaram do estudo. Todos estavam em regime de internação provisória.

\section{Consentimento livre e esclarecido}

Dado que o Poder Familiar encontrava-se temporariamente com o Estado, o Juiz da Vara da Infância e da Juventude concedeu uma autorização formal para cada adolescente. A intervenção foi realizada somente quando o adolescente concordou em participar do programa, estando claro que a não participação do mesmo não implicaria em quaisquer posturas punitivas ou coercitivas.

\section{Local}

O estudo foi conduzido em uma sala de atendimento psicoeducacional de uma instituição vinculada à Vara da Infância e da Juventude de uma cidade de porte médio do interior de São Paulo.

\section{Instrumentos de coleta de dados}

Instrumentos utilizados: Roteiro de Entrevista Inicial; Inventário de Depressão (BID - Beck, Rush, Shaw \& Emery, 1979); Escala de Transtorno de Raiva - ADS-VII (DiGiuseppe, Eskhardt, Tafrate, Robi \& Kopec, 1998 - versão traduzida e adaptada pelo primeiro autor); Escala de Auto-Estima (Rosenberg, 1965); Questionário de Avaliação do Programa de Intervenção; monitoramento de possíveis atos infracionais e registro do auto-relato dos participantes sobre estratégias trabalhadas durante a intervenção.

\section{Procedimento}

O estudo consistiu em 10 sessões individuais, sendo três sessões realizadas na fase de pré-teste e sete sessões na fase de intervenção. Em função do tempo médio de internação (15 dias), as sessões eram geralmente diárias com duração média de uma hora cada, sendo realizadas no período da manhã para minimizar possíveis interferências na dinâmica da instituição.

$\mathrm{Na}$ primeira sessão do pré-teste, foi aplicado o Roteiro de Entrevista Individual; na segunda sessão foi aplicado a Escala de Transtorno de Raiva - ADSVII e na terceira sessão da fase anterior à intervenção foi aplicada a Escala de Auto Estima e o Inventário de Depressão. Os adolescentes podiam optar entre realizar a leitura supervisionada dos instrumentos ou a leitura realizada pelo pesquisador.

As sessões do programa de intervenção foram baseadas nos trabalhos de D'Zurilla e Goldfried (1971), Hawton e Kirk (1997), Nezu e Nezu (1999), O'Leary, Heyman e Neidig (1999) e Padovani e Williams (2002). Em tal fase, o pesquisador inicialmente explicava os fundamentos da resolução de problemas e realizada uma série de exercícios para analisar o repertório inicial do participante e ensinar novas estratégias. Os exercícios envolviam: descrição dos eventos antecedentes ao comportamento infrator que causou a internação, análise das consequiências associadas ao evento, levantamento e análise de alternativas potencias, avaliação da alternativa selecionada e implicações da escolha para si próprio e para terceiros. Para facilitar o processo avaliativo era solicitado para o participante atribuir notas de 0 a 10 para cada alternativa, sendo 0 ausência de riscos e 10 máximo de risco. Paralelamente o pesquisador ensinava técnicas de relaxamento, análise de pensamentos disfuncionais, brainstorming e time-out. Explicava ainda, que a aplicação de tais estratégias seria de grande relevância no processo de prevenção de resposta automática. No final da sessão pesquisador enfatiza a importância de pensar nas consequiências antes de emitir qualquer comportamento que possa envolver riscos para si próprio e para terceiros. A Tabela 1 a seguir descreve os temas e atividades desenvolvidas em cada sessão. 
Tabela 1: Temas e atividades desenvolvidos em cada sessão

\begin{tabular}{|c|c|}
\hline Sessão & Tema / atividade \\
\hline 1 & Análise do repertório de resolução de problemas, identificação e aceitação da situação problema. \\
\hline 2 & $\begin{array}{l}\text { Levantamento de uma situação problema, lista de alternativas potenciais, brainstorming, levantamento e } \\
\text { análise das possíveis conseqüências. }\end{array}$ \\
\hline 3 & $\begin{array}{l}\text { Modelo cognitivo-comportamental da raiva, técnica de controle da raiva, opções de pensamentos, time- } \\
\text { out, treinamento auto-instrucional, relaxamento. }\end{array}$ \\
\hline 4 & $\begin{array}{l}\text { Identificação de sentimentos, prevenção de resposta automática, identificação de respostas somáticas, } \\
\text { levantamento de alternativas, técnicas de autocontrole, análise de consequiências, análise de crenças. }\end{array}$ \\
\hline 5 & $\begin{array}{l}\text { Levantamento de situação problema, reavaliação da situação, análise das possíveis consequiências, com- } \\
\text { binação de elementos na resolução de problema, time-out, prevenção de resposta automática, levanta- } \\
\text { mento de ganhos. }\end{array}$ \\
\hline 6 & Avaliação da intervenção. \\
\hline
\end{tabular}

$\mathrm{Na}$ fase de pós-teste (sétima sessão) eram reaplicados os instrumentos da fase de pré-teste. Por fim, era explanado que após três meses do término da intervenção o pesquisador iria entrar em contato para acompanhamento.

\section{RESULTADOS E DISCUSSÃO}

Três adolescentes tiveram $100 \%$ de presença no programa de intervenção, sendo que o participante 4 (P4) participou de $90 \%$ das atividades, alegando estar com dor de cabeça em uma sessão.

O perfil dos adolescentes envolvidos no programa de intervenção indicou história de fracasso e evasão escolar; envolvimento em lutas corporais e consumo de bebidas alcoólicas. Adicionalmente dois participantes $(\mathrm{P} 1, \mathrm{P} 3)$ relataram fazer uso de drogas ilícitas.

A estrutura familiar era caracterizada por membros que exerciam atividades profissionais com pouca qualificação com renda familiar entre 3-4 salários mínimos. Apenas um participante (P2) não indicou ocorrência de violência doméstica no âmbito familiar.

Ao consultar a base de dados da presente instituição constatou-se que P4 foi o participante que cometeu o maior número de infrações (sete infrações) e P2, o que cometeu o menor número (apenas uma infração). P3 foi o participante que cometeu o delito mais grave (homicídio doloso), sendo furto a infração mais freqüente entre os participantes.

A Figura 1 a seguir ilustra os escores obtidos por cada participante no Inventário de Depressão, Escala de Transtorno de Raiva e Escala de Auto-estima nas fases do estudo ao longo do estudo.

É possível notar um decréscimo dos escores de depressão obtidos por todos os participantes no pósteste. Na fase de follow-up, o participante 2 indicou ausência de sintomatologia depressiva. O participante $\mathrm{P} 3$, em contraste, indicou um aumento expressivo da depressão. Cabe explicar que P3, na ocasião do follow-up, estava internado na Febem em decorrência da infração cometida (homicídio doloso), explicando em parte o aumento da sintomatologia depressiva. O relato a seguir sustenta essa hipótese: "Já faz três meses. Não é fácil, não. Só na visita me sinto mais alegre". Adicionalmente, P3 referiu-se à relação empática estabelecida com o pesquisador ("Foi muito bom conversar com o senhor") e salientou o efeito positivo do programa de intervenção ("Você me ajudou a raciocinar mais certo").

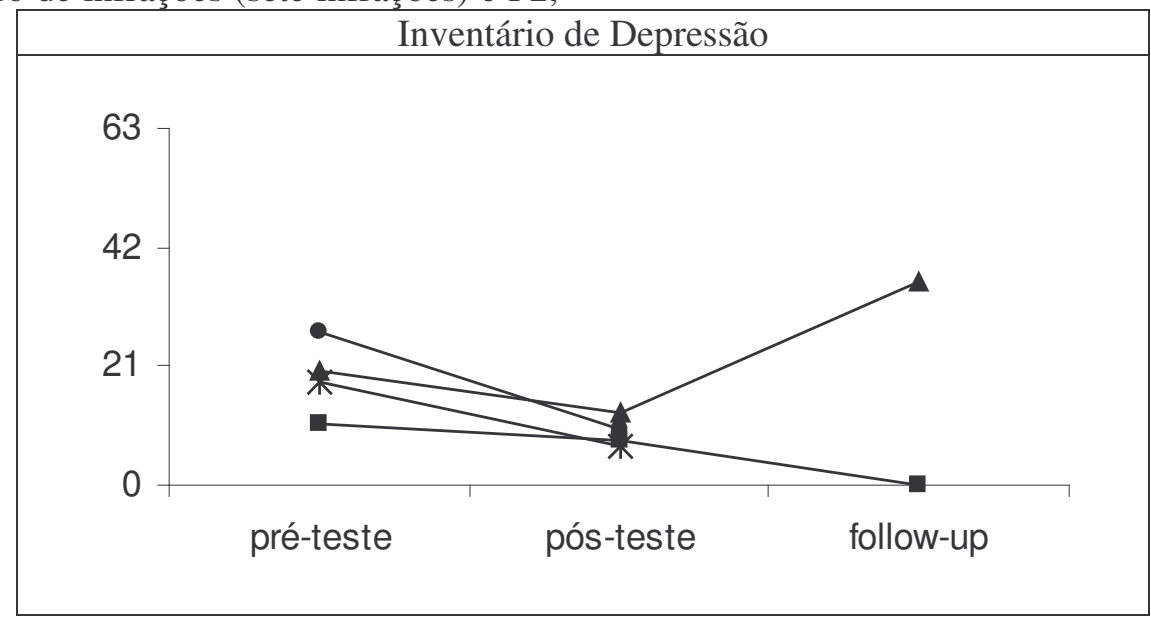



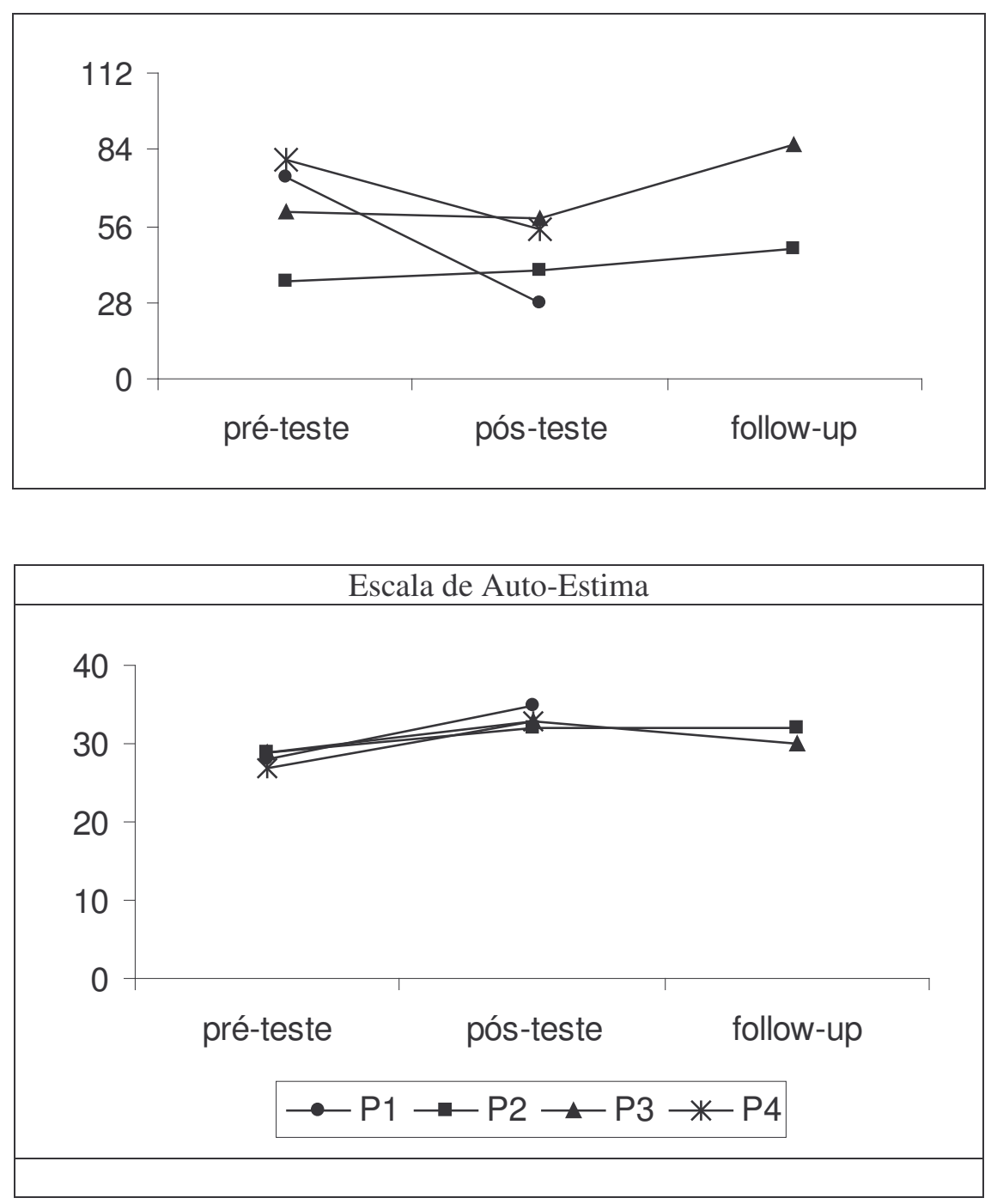

Figura 1: Desempenho dos participantes no Inventário de Depressão,

Escala de Transtorno de Raiva e Escala de Auto-estima nas fases do estudo.

Com relação ao desempenho de cada participante na Escala de Transtorno de Raiva (ADS-VII), verificou-se que metade dos participantes (P2 e P3) não apresentou mudanças marcantes no desempenho durante a fase de pré e pós teste. É possível que tais participantes, temendo à adoção de novas medidas punitivas e coercitivas, tenham minimizado e/ou evitado o relato de comportamentos que indicassem dificuldades para controlar a raiva. Outra hipótese seria que a intervenção não foi eficaz no controle da raiva.

Contrariando os dados da literatura (Patterson \& cols., 1992), verificou-se, conforme observado na Figura 1, que todos os participantes tiveram um desempenho adequado na Escala de Auto-Estima ao longo de todas as fases do estudo. Dentre as possíveis hipóteses para tal dado pode-se destacar: conseqüências positivas provenientes da infração, apesar de socialmente inadequada e o reforço social dos demais adolescentes mantidos em regime de internação (P3 era chamado pelos demais adolescentes de "homici- da", terminologia que parecia ser indicativa de respeito e medo).

Ao se analisar o repertório de resolução de problemas, foi possível verificar que os participantes estavam sob controle de consequiências reforçadoras imediatas e apresentavam estratégias de resolução de problemas socialmente inadequadas.

$\mathrm{Na}$ fase de levantamento dos eventos antecedentes ao comportamento infrator, P1 relatou que, diante da falta de dinheiro para ir a um show de Rap, emprestou um revólver para fazer um assalto: "Apontei o revólver para o bilheteiro do ônibus, catei o dinheiro e sai correndo. Cheguei em casa tomei um banho e fui para o show".

Fatos semelhantes foram observados com P3 que, apesar de indicar, inicialmente uma resposta adequada ignorando uma provocação, em um segundo momento, na presença de amigos, empregou uma solução inadequada. Segue o relato do participante sobre o ocorrido: "Eu estava sozinho na rua e o cara me tirou de bosta. Deixei quieto. No outro dia quando eu esta- 
va com meus amigos, ele apanhou. Depois disso nunca mais me tirou de bosta" (P3).

Em contrapartida, no levantamento de alternativas para a resolução de problemas, pode-se verificar que os adolescentes não encontraram dificuldades em criar soluções verbais socialmente adequadas. Diante da falta de dinheiro P1 relatou que poderia: "roubar, pedir dinheiro para o irmão, trabalhar e ficar com a cabeça no lugar". Elegeu trabalhar como alternativa mais adequada. Ao analisar as consequiências de trabalhar, acrescentou: "é excelente, não tem nenhum problema. Não ia internado, nem ficava sem liberdade". Nota-se, ainda, que o participante priorizou a decisão que não implicaria em conseqüências negativas ou risco para si próprio ou para os outros, além de garantir a maximização dos ganhos. Comportamentos semelhantes foram observados com os demais participantes.

Ainda em relação à falta de dinheiro, situação também vivenciada por P2 e que ocasionou a internação, o participante indicou como alternativas "assaltar, esperar até arrumar emprego, não assaltar e tentar arrumar dignamente". Escolheu como mais vantajosa a alternativa "esperar até arrumar um emprego". Relatou, ainda, que tal atitude não acarretaria em outros problemas e que, portanto, evitaria situações adversas e indesejáveis.

Quanto à problemática que envolvia ameaça de agressão de um estranho, P3 apontou: "Mexer com ele, deixar quieto, ir atrás dele depois, sair e deixar ele ficar amolando, sair de perto". Elegeu como alternativa mais ajustada "sair de perto", complementando ainda: "é lógico que é essa alternativa, mas raramente acontece comigo". Ao fazer tal comentário P3 indicou que, apesar de tal decisão se apresentar como a menos problemática, dificilmente ela aconteceria na realidade quando ele se deparasse com uma situação de provocação. Tal constatação pode ser indicativa de dificuldades no manejo de situações adversas, dificuldades de autocontrole e manejo de raiva, impulsividade e baixa tolerância à frustração. O presente relato também evidência a dificuldade de se mudar contingências reforçadoras estabelecidas, mesmo que envolvam riscos para si próprio ou para terceiros. Isso explica, em parte, a manutenção da transgressão independente do processo de punição (perda de liberdade) aplicado pelo sistema judicial. Portanto, fica evidente a necessidade de se desenvolver estudos para analisar e implementar a generalização de habilidades de resolução de problemas sociais com tal população.

Apenas dois participantes (P2 e P3) foram localizados no follow-up: P2 já havia cumprido a medida socioeducativa aplicada (Liberdade Assistida), sendo encontrado em seu domicílio e P 3, como mencionado, estava internado em uma unidade da Febem $(\mathrm{O}$ pesquisador foi informado por um parente de P1 que o adolescente estava morando em outra cidade do interior paulista, juntamente com o pai, para ficar "longe das más companhias". P4 foi procurado na Liberdade Assistida, mas o adolescente faltara na reunião previamente agendada com o técnico responsável pelo acompanhamento da medida).

Para os dois participantes localizados na fase de follow-up (P2, P3), observou-se um aumento dos escores no instrumento de mensuração de raiva. Dentre as hipóteses explicativas para tal, pode-se destacar que $\mathrm{P} 2$, tendo cumprido a medida judicial, não temeu a exposição de comportamentos que indicassem dificuldades no controle da raiva. Para P3, supõe-se, que a estrutura e o ambiente coercitivo da Febem, tenham contribuído para o referido aumento do escore de raiva. Em contraste, o nível de depressão aumentou apenas para $\mathrm{P} 3$ que continuava internado.

Em relação ao monitoramento de outros atos infracionais, notou-se ausência de infrações em três dos participantes e uma infração de menor gravidade (quebra de medida socioeducativa) para o $4^{\circ}$ participante, o que é promissor.

Entre as variáveis que possivelmente contribuíram para o desenvolvimento do estudo pode-se destacar: espaço para verbalizações sem medidas coercitivas, estabelecimento de uma relação empática com o primeiro autor e o próprio deslocamento da unidade de internação à sala de atendimento.

Todos os participantes avaliaram a intervenção positivamente. O participante 4 relatou: "Achei 10. Foi muito bom para mim. Me ajudou a refletir sobre o meu pensamento e minha vida". P3 relatou ter ficado satisfeito com o atendimento recebido, concluindo: "Você me deu muitas alternativas. Gostei de ter participado".

\section{CONCLUSÕES}

O presente estudo mostrou que é possível intervir com essa população marginalizada e temida pela sociedade. Entretanto, seria conveniente a condução de projetos de pesquisas que avaliem de modo sistemáticos aqui obtidos. Tais projetos poderiam envolver sessões de observação dos adolescentes em atividades e a utilização de recursos audiovisuais ou computacionais envolvendo estratégias de resolução de problema. São necessários esforços contínuos da ciência, do Estado e do Sistema Judicial para melhor atender tal população que aflige toda a sociedade. 


\section{REFERÊNCIAS}

Beck, A. T., Rush, A. J., Shaw, B. F. \& Emery, G. (1979). Cognitive therapy of depression: a treatment manual. New York: Guilford Press.

Carvalho, M. C. N. (2003). Efeito das práticas educativas parentais sobre o comportamento infrator do adolescente. Dissertação de Mestrado. Curso de Pós-Graduação em Psicologia. Universidade Federal do Paraná. Curitiba, PR.

Di Giuseppe, R., Eckhardt, C., Tafrate, R., Robin, M. \& Kopec, A. M. (1998). The anger disorders scale: a new measure for the assessement of anger disorders. Manuscrito submetido para publicação.

D’Zurilla, T. J. \& Goldfried, M. R. (1971). Problem solving and behavior modification. Journal of Abnormal Psychology, 78, 107-126.

Feldman, M. P. (1979). Comportamento criminoso. Rio de Janeiro: Zahar.

Gomide, P. I. C. (1990). Análise do processo de integração do menor infrator ao meio social. Dissertação de Doutorado, Universidade de São Paulo. São Paulo, SP.

Gomide, P. I. C. (2003). Estilos parentais e comportamento antisocial. Em A. Del Prette \& Z. A. P. Del Prette (Orgs.), Habilidades Sociais, desenvolvimento e aprendizagem (pp. 21-60). Campinas: Alínea.

Hawton, K. \& Kirk, J. (1997). Resoluções de problemas. Em K. Hawton, P. M. Salkovskis \& D. M. Clark. (Orgs.), Terapia cognitivo-comportamental para problemas psiquiátricos - um guia prático (pp. 574-604). São Paulo: Martins Fontes.

Huizinga, D., Loeber, R., Thornberry. \& Cothern, L. (2000). Co-occurrence of deliquency and other problem behavior. Juvenile Justice Bulletin. Obtido em 20 de julho de 2002 do World Wide Web: http://www.ojjdp.ncjrs.org/ccd/index.html.

Kaplan, H. I., Sadock, B. I. \& Grebb, J. A. (1997). Compêndio de psiquiatria: ciências do comportamento e psiquiatria clínica ( $7^{\mathrm{a}}$ ed.). Porto Alegre: Artes Médicas.
Kauffman, J. M. (2001). Characteristics of emotional and behavioral disorders of children and youth. Englewood Cliffs, N. J.: Merrill Prentice Hall.

Meichenbaum, D. (2001). Treatment of individuals with angercontrol problem and aggressive behaviors: a clinical handbook. Institute Press: Florida.

Nezu, A. M. \& Nezu, C. M. (1999). Treinamento em solução de problemas. Em V. E. Caballo (Org.), Manual de técnicas de terapia comportamental e modificação de comportamento (pp. 471-493). São Paulo: Santos.

O’Leary, K. D., Heyman, R. E. \& Neidig, P. H. (1999). Treatment of wife abuse: a comparison of gender-specific and conjoint approaches. Behavior Therapy, 30, 475-505.

Padovani, R. C. \& Williams, L. C. A. (2002). Intervenção psicoterapêutica com agressor conjugal: um estudo de caso. Psicologia em Estudo, 7, 13-17.

Patterson, G. R., Reid, J. B. \& Dishion, T. J. (1992). Antisocial boys. Oregon: Castalia Publishing Company.

Reid, J. B. \& Eddy, M. (2002). Interventions for antisocial behavioral: overview. Em J. B. Reid, G. R. Patterson \& J. Snyder, Antisocial behavioral and adolescents: a developmental analysis and model for intervention (pp. 195201).Washington: American Psychological Association.

Rosenberg, M. (1965). Society and the adolescent self image. Princeton: University Press.

Enviado: 01/09/2004 $1^{a}$ Revisão : $21 / 01 / 2005$ $2^{a}$ Revisão : $14 / 02 / 2005$ Aceito: 14/03/2005

\section{Sobre os autores:}

Ricardo da Costa Padovani: Universidade Federal de São Carlos. Endereço eletrônico: ricardopadovani @ netsite.com.br.

Lúcia Cavalcanti de Albuquerque Williams: Professora da Universidade Federal de São Carlos. CECH. Departamento de Psicologia. LAPREV (Laboratório de Análise e Prevenção à Violência). 
